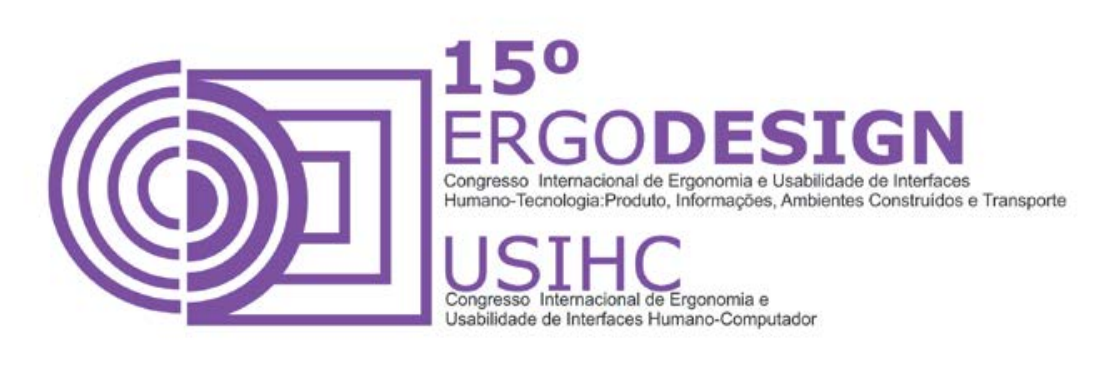

\title{
APLICATIVO PARA AUXÍLIO NO TRATAMENTO DE CRIANÇAS COM DISLEXIA
}

\section{APP AS AN AID FOR THE TREATMENT OF DYSLEXIC CHILDREN}

\author{
BITTENCOURT, Teresa (1); \\ SAVINO, João (2); \\ FERNANDES, Helena (3); \\ REBELLO, Luiza(4); \\ AMADO, Giuseppe (5)
}

(1) Graduando, UFF

e-mail: teresa bitten@yahoo.com.br

(2) Graduando, UFF

e-mail: savinojoao@gmail.com

(3) Graduando, UFF

e-mail: heleninha.fgf@hotmail.com

(4) D.Sc., UFF

e-mail: luizarebello@id.uff.br

(5) D.Sc., UFF

e-mail: gamado@id.uff.br

\begin{abstract}
RESUMO
Este trabalho tem como objetivo desenvolver um aplicativo para tablets a fim de auxiliar o tratamento de crianças com dislexia, levando em consideração a relação entre o usuário, a fonoaudióloga e os pais durante o tratamento. Através do estudo ergonômico e do acompanhamento de diferentes etapas do processo de tratamento, foi desenvolvido um aplicativo para crianças de idade entre seis e nove anos, focado nas principais áreas a serem desenvolvidas durante o tratamento.

Palavras-chave: Crianças, Dislexia, Aplicativo.
\end{abstract}




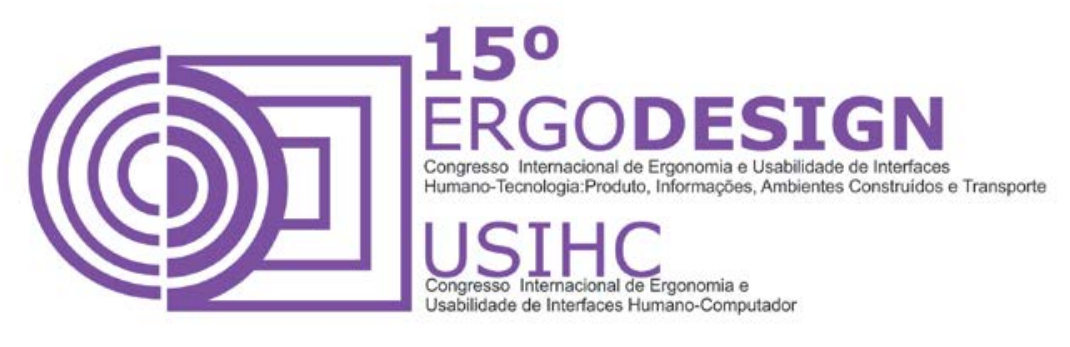

ABSTRACT

This paper aims to show the develop an application for tablets in order to assist the treatment of children with dyslexia, taking into consideration the relationship between the user, the speech therapist and parents during treatment. Through the ergonomic study and monitoring of different stages of the treatment process, an specific application was developed for children of age between six and nine years, focused on the main areas to be developed during treatment.

Keywords: Children, Dyslexia, App.

\section{INTRODUÇÃO}

A Dislexia é um tipo de transtorno de aprendizagem, específica da área da linguagem. Caracteriza-se por dificuldades linguísticas variadas, incluindo normalmente, além das alterações de leitura, um problema com a aquisição da proficiência da escrita e soletração, apesar do indivíduo possuir inteligência normal e ser exposto ao aprendizado adequado. Tem origem neurobiológica, e base genética de origem hereditária, com isso entende-se a Dislexia como um funcionamento peculiar do cérebro durante o processamento da linguagem. Portanto, envolve dificuldades em três áreas básicas, são elas: consciência fonológica, acesso lexical e memória fonológica.

Apesar de ser o distúrbio de aprendizado mais frequentemente identificado em sala de aula no Brasil nunca foi feito um estudo com abrangência nacional e amostragem significativa. Os dados mais próximos, e utilizados como base pelo instituto ABCD (organização social voltada para a dislexia e outros transtornos de aprendizagem), são de Portugal, devido à semelhança do idioma. Em Portugal 5\% da população têm dislexia, comparativamente estima-se que no Brasil aproximadamente $4 \%$ da população possua dislexia. No mundo também não existe um consenso quanto à porcentagem de disléxicos, sendo esse valor influenciado pelo critério de diagnóstico utilizado e o sistema linguístico de cada país. Porém, estima-se que 10 a 15\% da população apresente dislexia.

O diagnóstico é feito por uma equipe multidisciplinar, que pode ser composta por diversos profissionais, entre eles psicólogos, psicopedagogos, fonoaudiólogos, e de forma clínica e por exclusão. Apesar de não ter cura, os tratamentos trazem melhorias significativas, pois utilizam métodos pedagógicos que visam desenvolver as áreas prejudicadas, minimizando assim as dificuldades do indivíduo. Porém, o tratamento não deve se restringir apenas à clínica, é necessário o envolvimento da família e escola a fim de estimular a criança continuamente.

O mercado, particularmente o brasileiro, não conta com muitos recursos disponíveis para auxílio no tratamento de crianças especialmente quando ainda na fase inicial do tratamento. Dessa forma, com o objetivo de desenvolver uma ferramenta que auxilie no tratamento de crianças com Dislexia. Foram feitas visitações à Arte Expressão, um centro de desenvolvimento e aprendizagem, que oferece serviços de fonoaudiologia, psicologia, psicopedagogia, avaliação neuropsicológica, reforço escolar, entre outros. O local, no momento, realizava o atendimento 


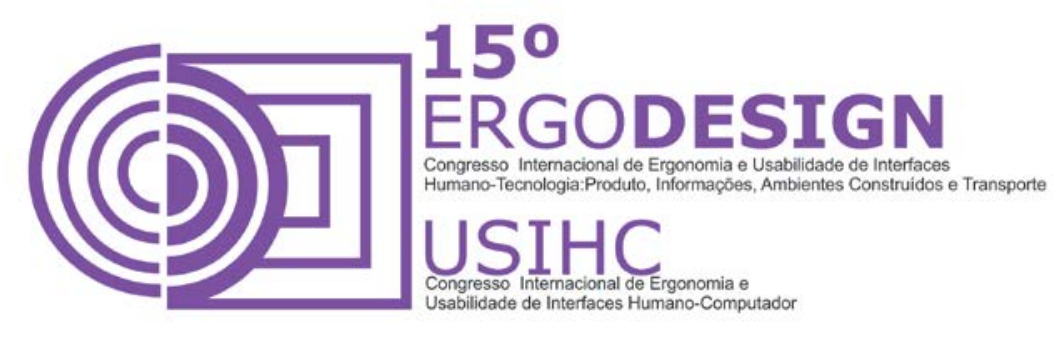

de nove pacientes disléxicos, entre crianças e adolescentes, foram feitas visitas constantes à duas crianças (entre seis e nove anos) e uma adolescente, com isso, tivemos acesso às diferentes etapas do tratamento. Todas as etapas do processo foram acompanhadas pelas fonoaudiólogas responsáveis pelo tratamento na clínica.

\section{DESENVOLVIMENTO}

\subsection{Visitações}

Para aprimorar os conhecimentos práticos a respeito do tema e vivenciar as etapas do tratamento, observando assim atividades realizadas e as reações das crianças às essas atividades, foram feitas visitas a duas crianças e uma adolescente, apesar desta não estar na faixa etária que optamos em trabalhar, 6 a 9 anos, ela possui uma dificuldade maior na área de memória operacional, um dos campos abordados pelo projeto. As duas crianças acompanhadas possuíam a mesma idade, 8 anos, porém a menina já estava em uma etapa mais avançada do tratamento por ter recebido o diagnóstico mais previamente, o menino havia começado a pouco o tratamento e apresentava um grau mais severo de dislexia.

Com o acompanhamento, observou-se que muitas vezes as crianças se sentem desmotivadas quando as atividades são feitas inteiramente no papel, e os pais tem fundamental importância no desenvolvimento do tratamento dos filhos. Por essas razões optou-se por desenvolver uma forma de auxílio ao tratamento da dislexia de forma lúdica e interativa, além de promover o contato dos pais no desenvolvimento da criança ao executar atividades em casa.

As observações feitas durante as visitações apontaram para os seguintes parâmetros para realização do projeto:

- A atividade deve se parecer com uma brincadeira;

- Ter um objetivo ou algo que desafie a criança a permanecer na atividade, mesmo quando não estiver na sessão com a fonoaudióloga;

- As atividades desenvolvidas devem se assemelhar com as atividades já realizadas no local;

- Em casa, a atividade deve integrar os pais, motivando assim também a participação destes com o tratamento dos filhos.

\subsection{Desenvolvimento}

Foi proposto pelas fonoaudiólogas que trabalhássemos em três áreas para o desenvolvimento de alternativas, as áreas auditiva, visual e de memória operacional. Dessa forma optou-se por utilizar o método de brainstorm para geração de alternativas. Em seguida, foi feita a seleção dos jogos a serem desenvolvidos e por fim classificados em ordem de prioridade, devido ao curto prazo para realização do projeto. 


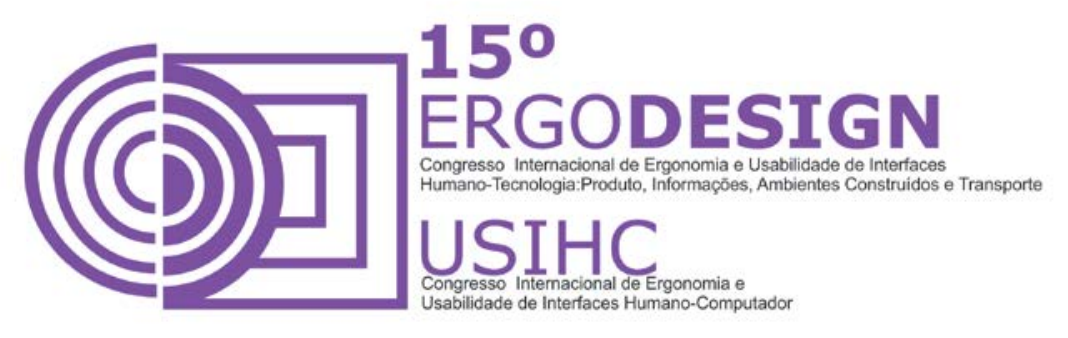

O primeiro jogo desenvolvido foi a "Corrida", o jogo visa trabalhar a área auditiva, mais especificadamente a contagem de sílabas. O jogo deverá ser feito em dupla, estimulando o envolvimento dos pais em casa. O jogo consiste em contar o número de sílabas das três palavras apresentadas, você andará o número de casas referente ao número de sílabas da palavra escolhida. Dessa forma a criança terá não apenas que contar as sílabas, mas também pensar em escolher aquela que irá possibilitar ela a andar mais casas. Caso o jogador erre o número de sílabas ele terá mais uma chance, já que muitas vezes as crianças se mostraram impulsivas durante as atividades, e é importante que a criança tenha a chance de localizar e corrigir seus erros.

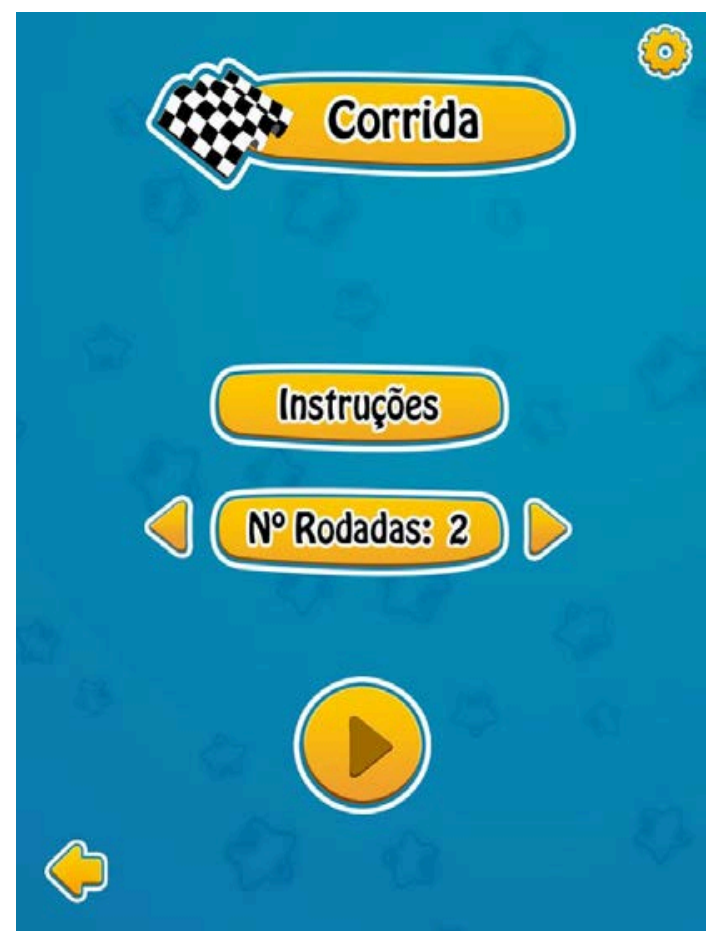

Figura 1: Tela de início do jogo corrida

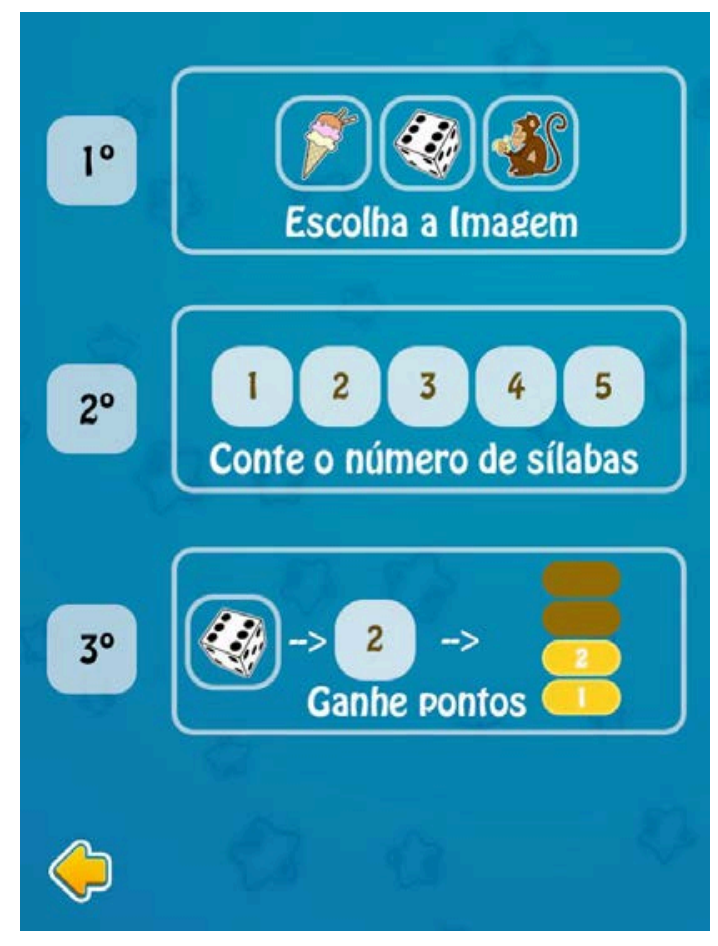

Figura 2: Tela de instruções do jogo corrida

Com o desenvolvimento básico do aplicativo fizemos testes com algumas crianças, as fonoaudiólogas e até mesmo pessoas externas ao projeto, a fim de levantar equívocos cometidos e sugestões de melhoria ao projeto. Pequenas alterações foram feitas quanto à possibilidade de escolher o número de rodadas, aumentando a competitividade e dando a fonoaudióloga a possibilidade de regular o tempo da atividade, e a exposição da grafia da 


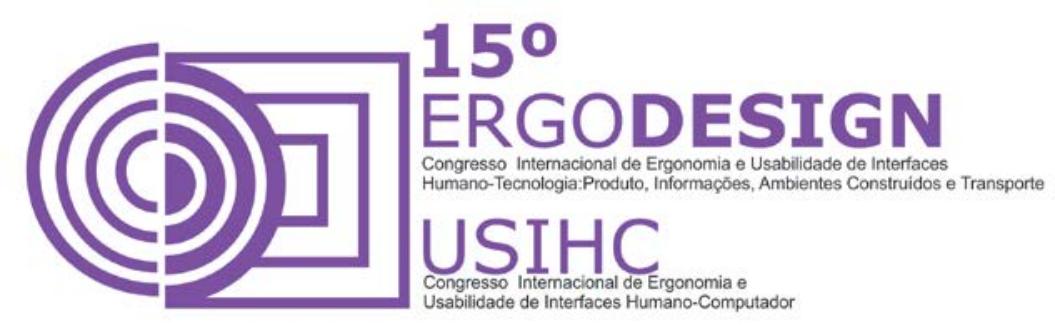

palavra após um erro, para que a criança pudesse visualizar seu equívoco e em seguida corrigilo.

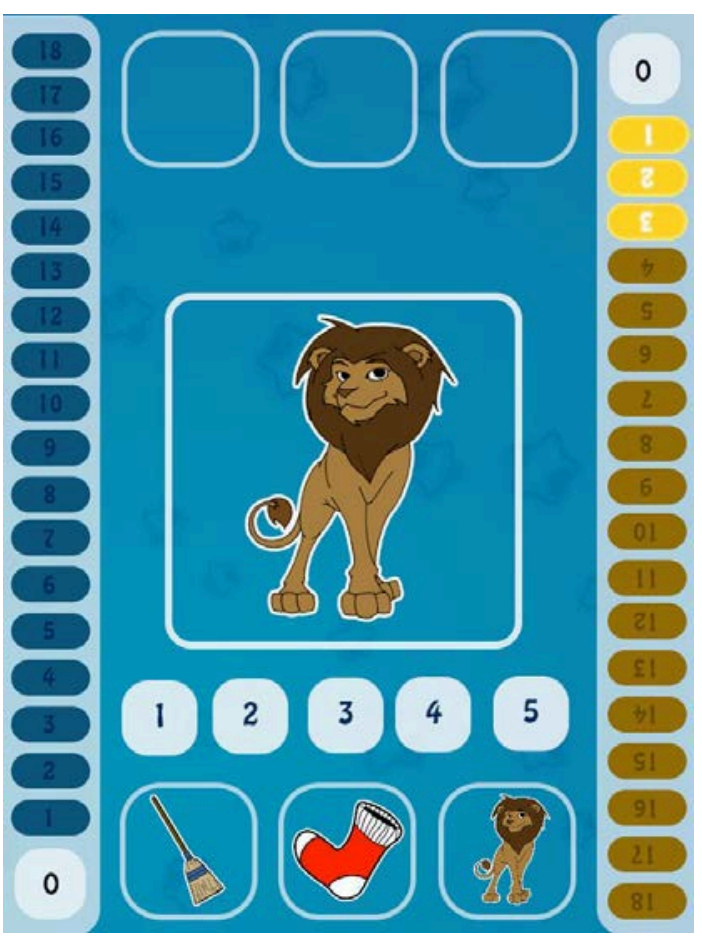

Figura 3: Tela do jogo corrida

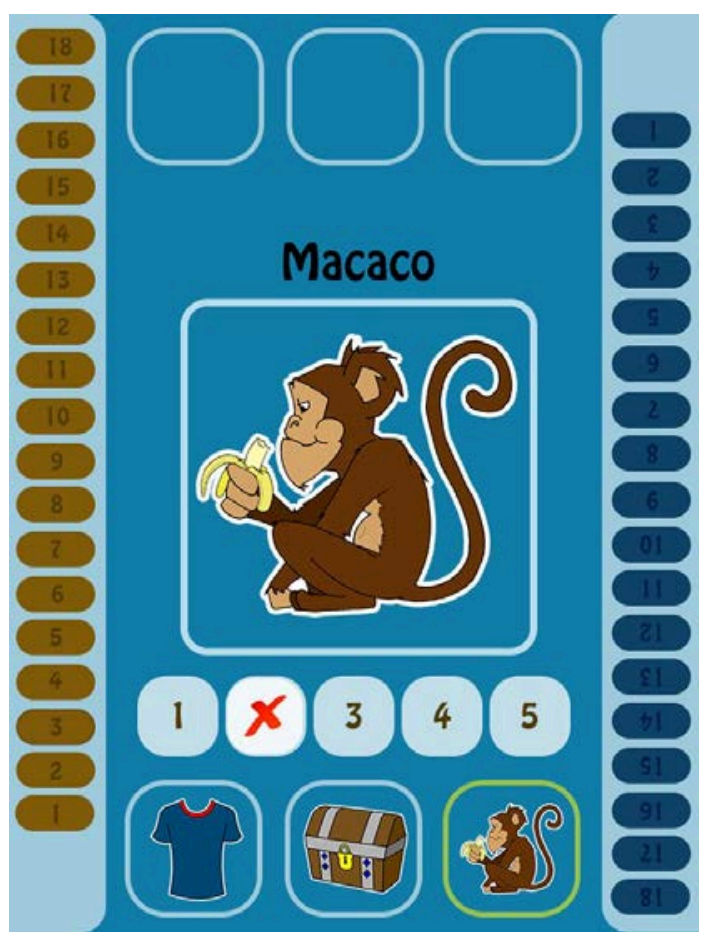

Figura 4: Tela do jogo corrida quando o usuário seleciona uma opção incorreta 

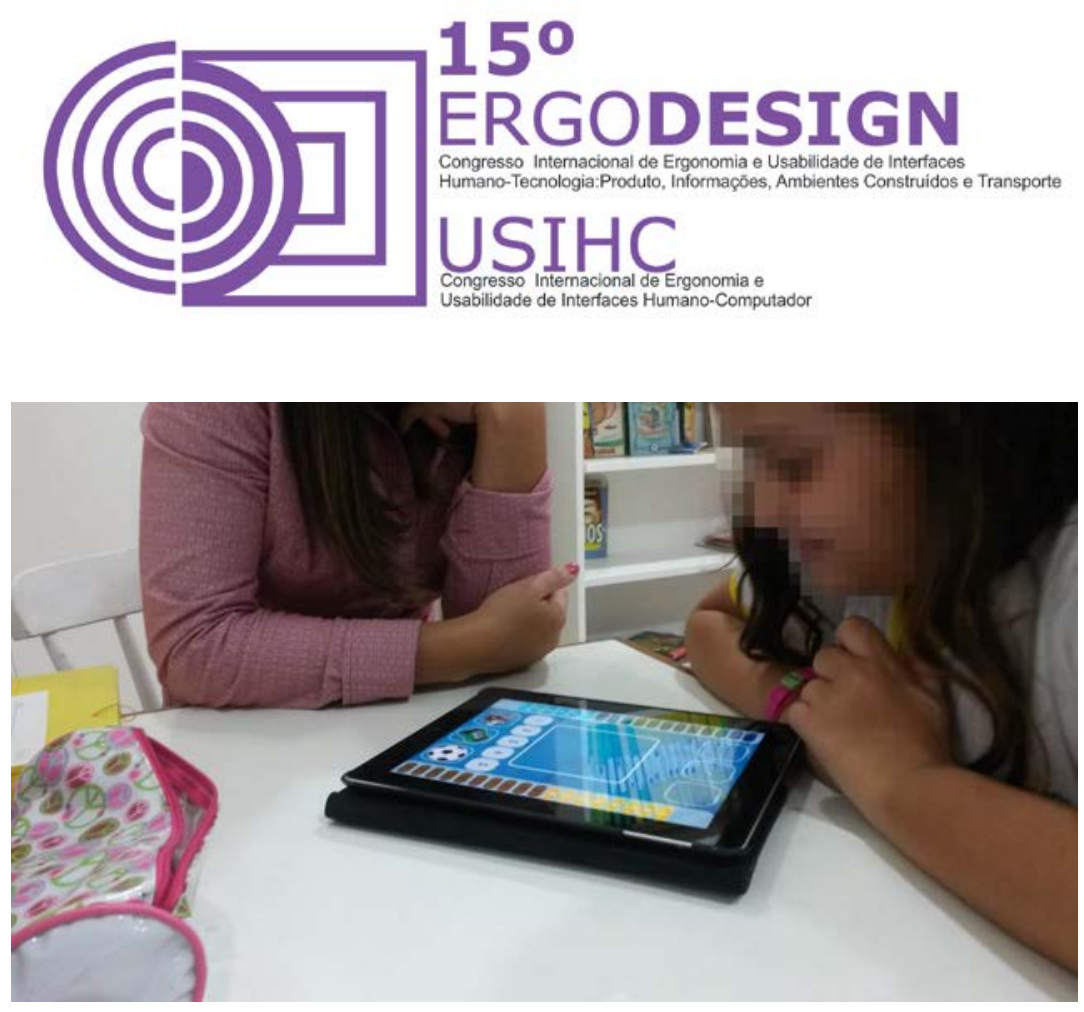

Figura 5: Teste com usuário.

Em seguida foi desenvolvido o jogo "Memória", que visa trabalhar a memória operacional, ou seja, de curto prazo. Com isso é apresentada uma sequência de imagens, que em seguida deve ser repetida com o uso de um tabuleiro fixo com diversas imagens. 


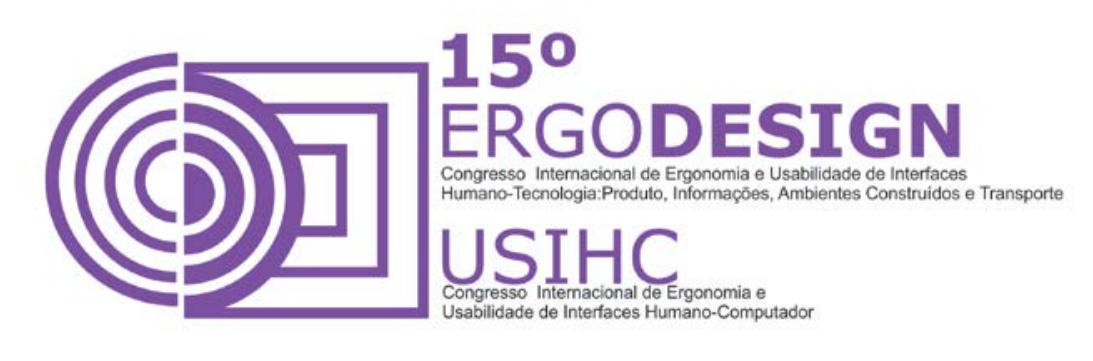

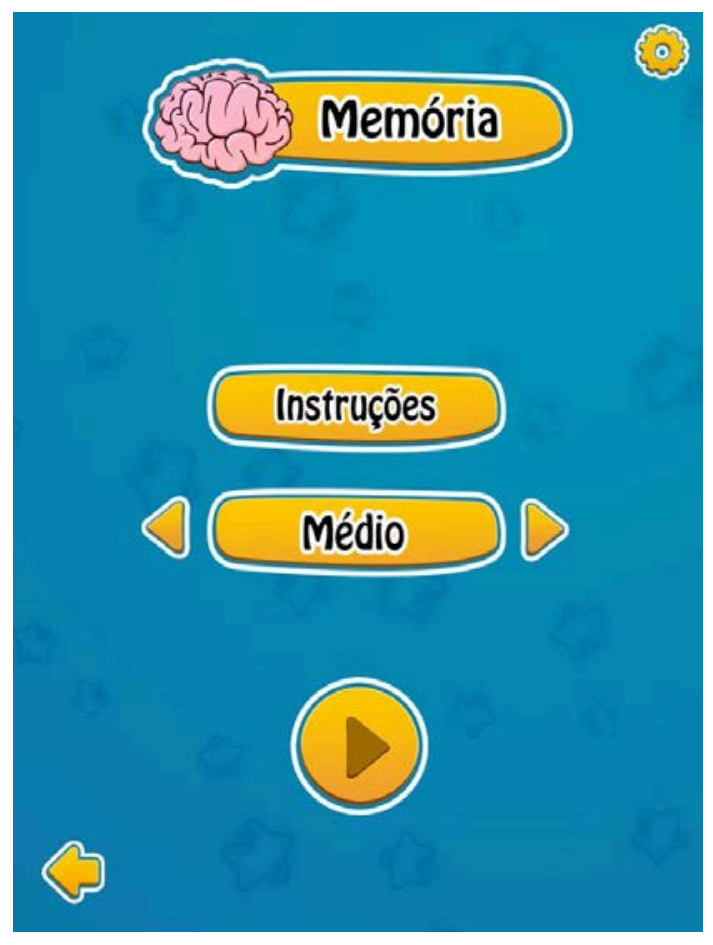

Figura 6: Tela de Início do jogo memória

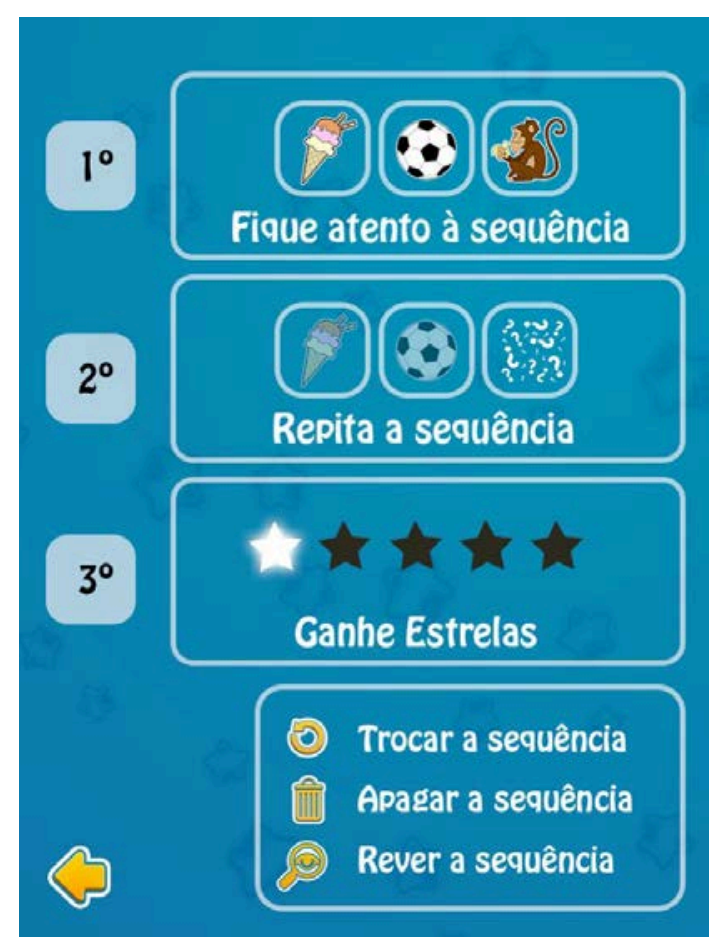

Figura 7: Tela de instruções do jogo memória 


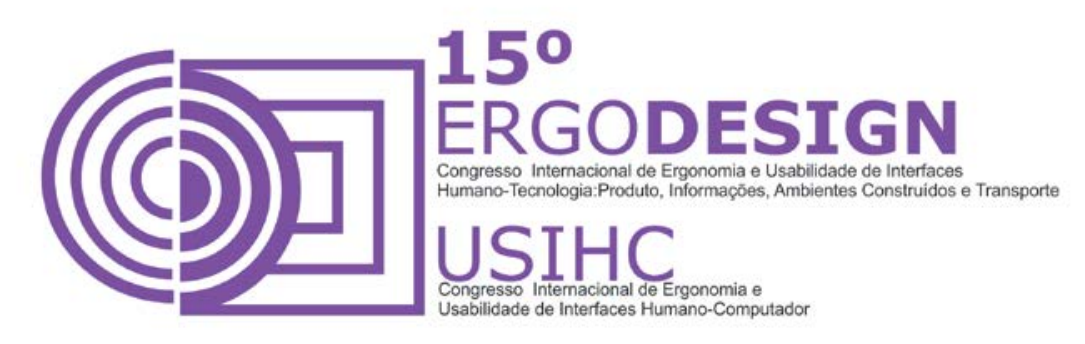

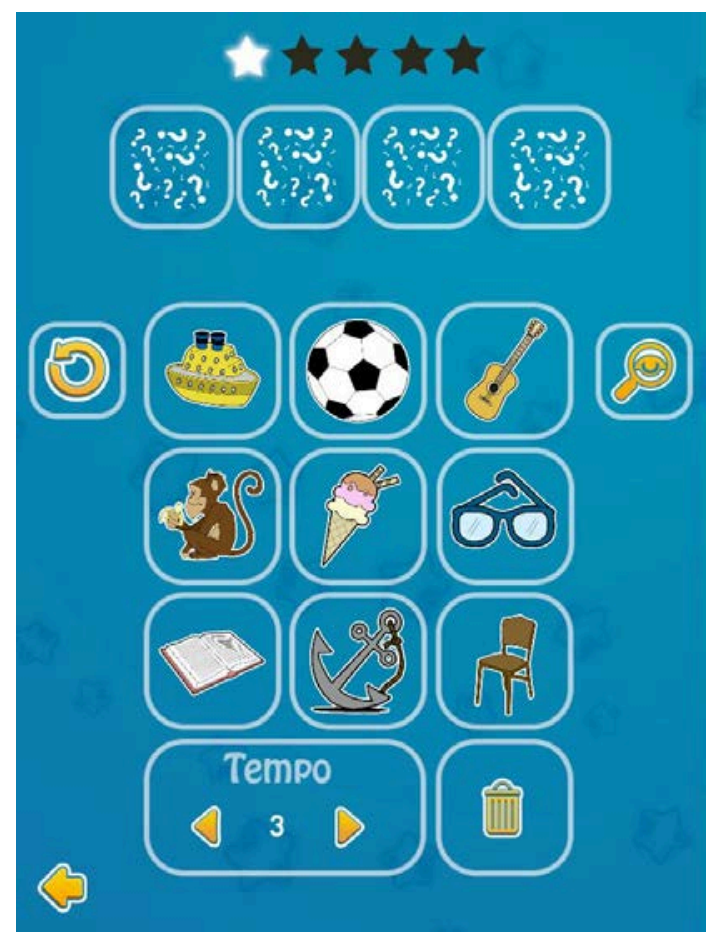

Figura 8: Tela do jogo memória

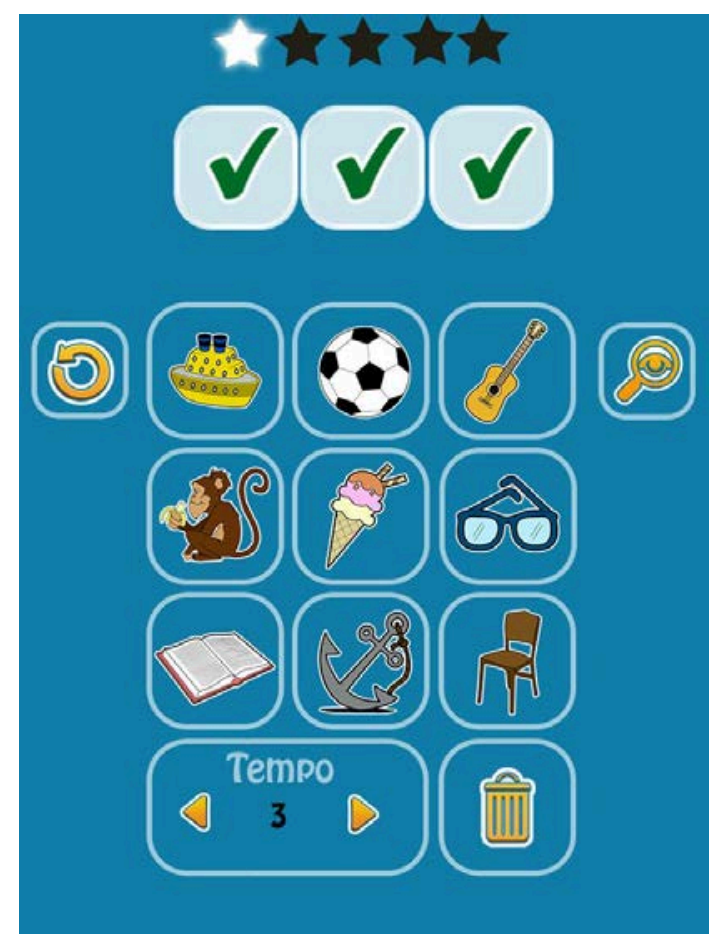

Figura 9: Tela do jogo memória quando usuário completa uma sequência correta

Durante o desenvolvimento, o jogo foi testado junto às crianças e suas fonoaudiólogas, a fim de incorporar as recomendações de ambos. A partir de então, foram incorporadas funções como 0 controle sobre o tempo de exposição das sequências, alterando assim a dificuldade do jogo, assim como a troca e adição de alguns ícones na tela. A alteração seguinte partiu da necessidade de mais uma forma de controlar a dificuldade do jogo, foram colocadas três fases, a primeira contava com a exposição de três imagens a segunda com quatro imagens e a terceira com cinco imagens. Por fim foi adicionado o sistema de pontuação por estrelas, no intuito de estimular o jogador durante a atividade através de uma forma de recompensa imediata. 


\section{(C)]}

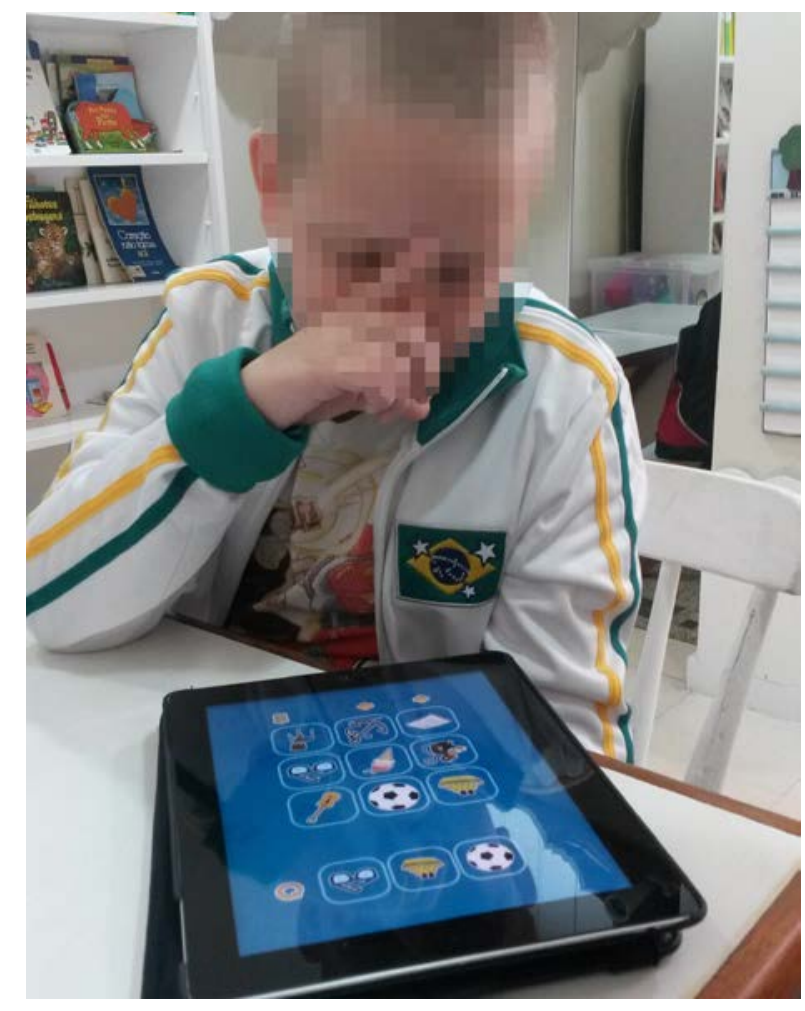

Figura 10: Teste com usuário.

\section{CONSIDERAÇÕES FINAIS}

Apesar de ser o distúrbio mais frequentemente identificado em sala de aula, a dislexia ainda carece de atenção. Professores capacitados a identificar tais dificuldades são indispensáveis, e as escolas precisam estar preparadas, assim como os pais.

A escolha pelo desenvolvimento de um aplicativo se mostrou como um diferencial, por ser uma área dinâmica e moderna, que se insere no contexto atual das crianças. Dessa forma, focou-se no desenvolvimento de uma ferramenta que auxiliasse não apenas no tratamento junto à fonoaudióloga, como também no contato dos pais no tratamento de seus filhos, sempre buscando a motivação por parte da criança através de uma atividade lúdica. Os resultados se mostraram satisfatórios, ao passo que durante os testes as crianças não apenas se mostraram motivadas com os desafios apresentados nos jogos, como também demonstraram evoluções. Durante o teste do jogo "Corrida", feito com um paciente que no momento estava treinando a separação de sílabas de palavras como "pato" e "lago", durante o jogo ele não apresentou grandes dificuldades inclusive na separação de palavras grandes como "abacaxi". Dessa forma, 


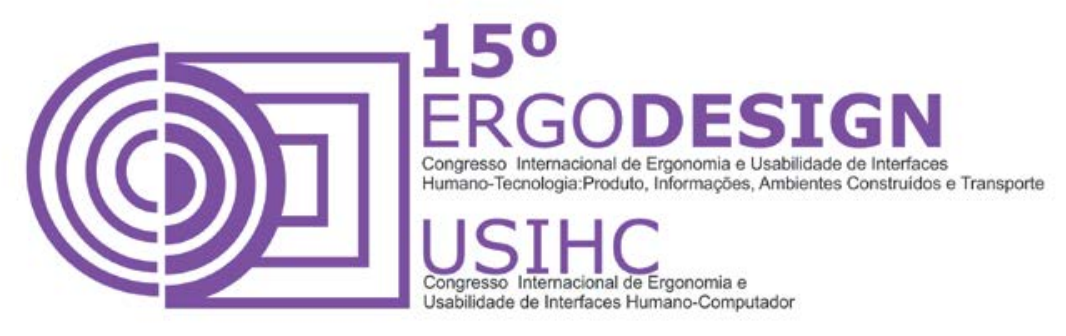

esperamos que por meio deste projeto tenhamos contribuído no auxílio ao tratamento de crianças com dislexia.

\section{REFERÊNCIAS BIBLIOGRÁFICAS}

http://www.cienciahoje.pt/index.php?oid=38852\&op=all - Acesso em 07/04/14

http://www.edac.com.br/artigos/lerNews.php?news_id=35 - Acesso em 07/04/14

http://idgnow.com.br/internet/2013/11/26/designer-cria-fonte-especial-de-caracteres-para-ajudar-

dislexicos/ - Acesso em 11/03/14

https://www.behance.net/gallery/Pook-Projeto-Academico-para-criancas-com-Dislexia/9352617 - Acesso em 27/04/14

http://pt.slideshare.net/clauftavares/dislexia-e-tecnologia - Acesso em 08/02/2014

http://todosaprendem.com.br/ - Acesso em 18/03/14

http://www.ncld.org/types-learning-disabilities/dyslexia/what-is-it-like-to-be-dyslexic-videos - Acesso em $19 / 03 / 14$

http://dislexiabrasil.com.br/secao3/auxilios-tecnologicos/ - Acesso em 19/03/14

http://agencia.fapesp.br/15080 - Acesso em 24/03/14

http://psiquecienciaevida.uol.com.br/ESPS/Edicoes/69/artigo235516-1.asp - Acesso em 24/03/14

http://www.individualmente.com.br/ - Acesso em 12/04/14

http://hypescience.com/cientistas-analisam-o-cerebro-de-criancas-para-estudar-dislexia/ - Acesso em $13 / 04 / 14$

http://www.neuroclin.com.br/dislexia.html - Acesso em 13/04/14

http://filosofiacienciaevida.uol.com.br/ESPS/Edicoes/38/imprime127924.asp - Acesso em 13/04/14

http://www.douradosagora.com.br/noticias/ciencia-e-saude/dislexicos-tem-talentos-especiais-diz-kiyoshirachi - Acesso em 14/04/14

http://pt.slideshare.net/huxleydias/as-10-heursticas-de-nielsen - Acesso em 05/05/14 http://www.interfaceando.com/usabilidade-para-websites/metodos-para-avaliacao-deusabilidade/avaliacao-heuristica/ - Acesso em 05/05/14

http://kids.pplware.sapo.pt/kids/apps-para-ajudar-criancas-com-dificuldades-de-aprendizagem-parte-i/ Acesso em 06/06/14

http://pplware.sapo.pt/pessoal/ciencia_saude/ipad-16-aplicacoes-para-ajudar-criancas-com-deficienciaparte-i/ - Acesso em 06/03/14 


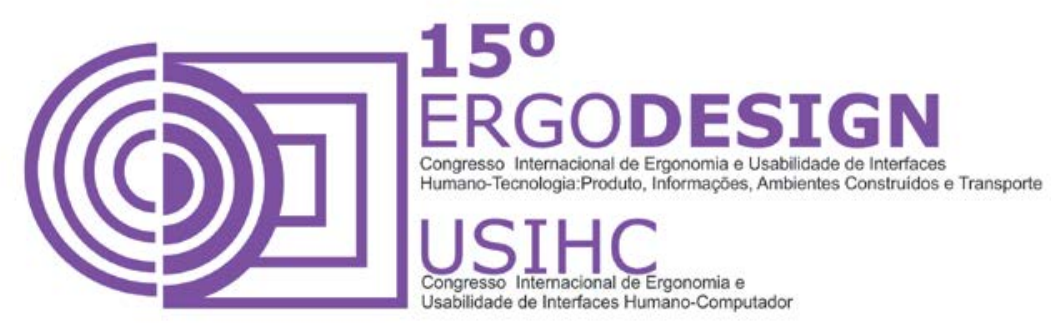

Silva, Cláudia da. Eficácia de um programa de remediação fonológica e leitura em escolares com distúrbio de aprendizagem.Marília, 2009. 197 f. Dissertação (Mestrado em Educação) - Faculdade de Filosofia e Ciências, Universidade Estadual Paulista, 2009. Orientador: Dra. Simone Aparecida Capellini.

Abreu, Sónia Isabel Alves de. Dislexia - aprender a aprender - Lisboa, 2012. 116 f. Dissertação de mestrado - Escola Superior de Educação Almeida Garrett, 2012. Orientador: Rafael Silva Pereira.

Chico, Paulo; Mousinho, Renata. Para aprender a ler a dislexia. www.folhadirigida.com.br - Caderno de educação. 7 a 13 de junho de 2011.

Mousinho, Renata. Conhecendo a Dislexia. Revista SINPRO - Rio - Abril, 2004. P. 26-33. 